\title{
Exploration of Cultivating mode of Creative and Interdisciplinary Talents for Engineering Students Based on Interdisciplinary Projects
}

\author{
Yang Renjie * (Corresponding Author) \\ College of Engineering and Technology \\ Tianjin Agricultural University \\ Tianjin, China \\ rjyang1978@163.com \\ Yang Yanrong \\ College of Engineering and Technology \\ Tianjin Agricultural University \\ Tianjin, China \\ 1605471320@qq.com
}

\author{
Dong Guimei \\ College of Engineering and Technology \\ Tianjin Agricultural University \\ Tianjin, China \\ 32568403@qq.com \\ Wei Yong \\ College of Engineering and Technology \\ Tianjin Agricultural University \\ Tianjin, China \\ $595183963 @ q q . c o m$
}

\begin{abstract}
The construction of innovative and interdisciplinary groups is of great significance to the cultivation of students' cooperation and innovation ability. The cultivating mode of creative and interdisciplinary talents for engineering students is proposed. Firstly, a high-level and interdisciplinary teacher's group was built from the aspects of teaching and researching environment, excitation mechanism, and responsibility system and team cooperation. Then, a high-level and interdisciplinary student's group was built from the aspects of the selection model, training model, incentive mode, and management model. Finally, the proposed methods of cultivating creative and interdisciplinary talents were evaluated. The proposed method makes the specialization and synthesis of professional education unify, cultivate students' different professional qualities and skills, form the organic composition of knowledge, quality and skill, so as to improve the comprehensive adaptability and innovation ability. The results can provide reference for the cultivating creative and interdisciplinary talents of other majors in other science and engine ering colleges.
\end{abstract}

Keywords-Higher-level, interdisciplinary talents, Teachers' interdisciplinary group, Students' interdisciplinary group, Engineering students

\section{INTRODUCTION}

For a long time, China's higher education has formed the traditional mode of "counterpart" professional education and "prescriptive" knowledge and skill education. These models are easier to adapt to the needs of specific posts. However, with the development of society and science and technology, the boundaries between the original subjects are constantly weakening. A large number of emerging interdisciplinary and marginal disciplines have emerged, and the interdisciplinary, permeable and integrated disciplines are becoming more and more extensive and deeper. Nowadays, more and more talents

1. The Major Teaching Reform Projects of Tianjin Agricultural University (2017-D-03)

2. Education Reform and Innovation Development Funds of Tianjin Agricultural University (20170202) are needed in the society, and the comprehensive quality of students is getting more and more attention. Therefore, the "one" types talents have gradually been unable to meet the needs of society, and the "ten" types talents are more and more popular. Interdisciplinary learning, cultivating students' comprehensive quality and cultivating compound talents have become the main demand of higher education [1].

The rapid development of contemporary science is increasingly dependent on the intersection and integration of different disciplines. Interdisciplinary is an inevitable trend of scientific development. Meanwhile, it is also an important way to enhance scientific and technological innovation and build an innovative country [2]. As early as the 80s of last century, people have realized the importance of cultivating creative and interdisciplinary talents. Many colleges and universities have begun to explore the feasibility of implementing the training program for cultivating creative and interdisciplinary talents. Japan proposes that higher education should exclude narrow professional consciousness, abandon professional differences and cultivate international talents. In China, many universities also implement the training program for cultivating creative and interdisciplinary talents. In 1984, the Zhejiang University set up a teaching reform class, which gathered the students of different specialties together. The guiding ideology of "strengthening the foundation, desalination of professional differences" and "high starting point, new content, fast progress, emphasis on training ability" was carried out. Relying on major scientific research projects, Hunan University implements the training mode of "2.5+1.5" or " $3+1$ ", and establishes the interdisciplinary undergraduate innovation teams, optimizes the professional structure, and sets up interdisciplinary related specialties. The practice shows that the training mode of interdisciplinary talents has obvious advantages and characteristics, which can not only stimulate students' interest in learning, broaden the field of students' 
knowledge, cultivate students' ability to solve problems in many ways and angles, but also promote the coordinated development of students' knowledge, ability and quality [3-4].

At present, the interdisciplinary training of undergraduate students relies mainly on learning double degrees, or to acquire relevant knowledge of different specialties through a variety of means, such as the network (especially MOOC class) in most universities. Taking the undergraduates of the Engineering College of Tianjin Agricultural University as an example, combined with the students of the College of Basic Science, the paper proposed a training model for cultivating creative and interdisciplinary talent of engineering students based on the scientific research projects in the platform of the photoelectric detection and the agricultural environment laboratories. Through the construction of high level and interdisciplinary teacher's group, the construction of high level and interdisciplinary student's group, the construction of evaluation system of interdisciplinary talents, a training model was established to cultivate creative and interdisciplinary talent of engineering students.

\section{BUILDING A HIGH LEVEL AND INTERDISCIPLINA RY TEACHER'S GROUP}

On the basis of higher-level scientific research projects, and the platform of the photoelectric detection and the agricultural environment laboratories, high level and interdisciplinary teacher's group was built. The cultivating creative and interdisciplinary talent needs high level and interdisciplinary teacher's group. A high level and interdisciplinary teacher's group was built from the aspects of teaching and researching environment, excitation mechanism, responsibility system and team cooperation (Fig.1).

\section{A. Construction of teaching and researching environment}

The premise of interdisciplinary is the mastery of discipline foundation. Only when having a solid grasp of discipline, the disciplinary can be further carry out synthesis. The primary focus of the college curriculum is to optimize the basic courses and build a solid discipline platform for students [5-6]. At the same time, interdisciplinary teachers should impart knowledge from a comprehensive and systematic perspective, emphasizing the links between different disciplines. On the other hand, interdisciplinary teachers should teach students to solve a problem from a multidisciplinary perspective.

The construction of researching environment is one of the key factors for cultivating creative and interdisciplinary talent. Schools should create a harmonious scientific researching environment suitable for the development of interdisciplinary teacher's group. Schools should encourage cooperation among different professional teachers in different faculty, and strengthen the construction of innovation platform, and increase funding for innovation teams. Our interdisciplinary teacher team consists of 5 different professional teachers coming form three different faculty.

\section{B. Construction of excitation mechanism}

Mobilizing the enthusiasm of teachers is the key to build high level and interdisciplinary teacher's group. The school should establish a sound system of teacher assessment and scientific research reward system, so that young teachers should be transformed from passive scientific research into active scientific research and mobilize their scientific research initiative. For young teachers with scientific research ability, schools should reduce the workload of teaching so that they can have the energy to carry out scientific research work.

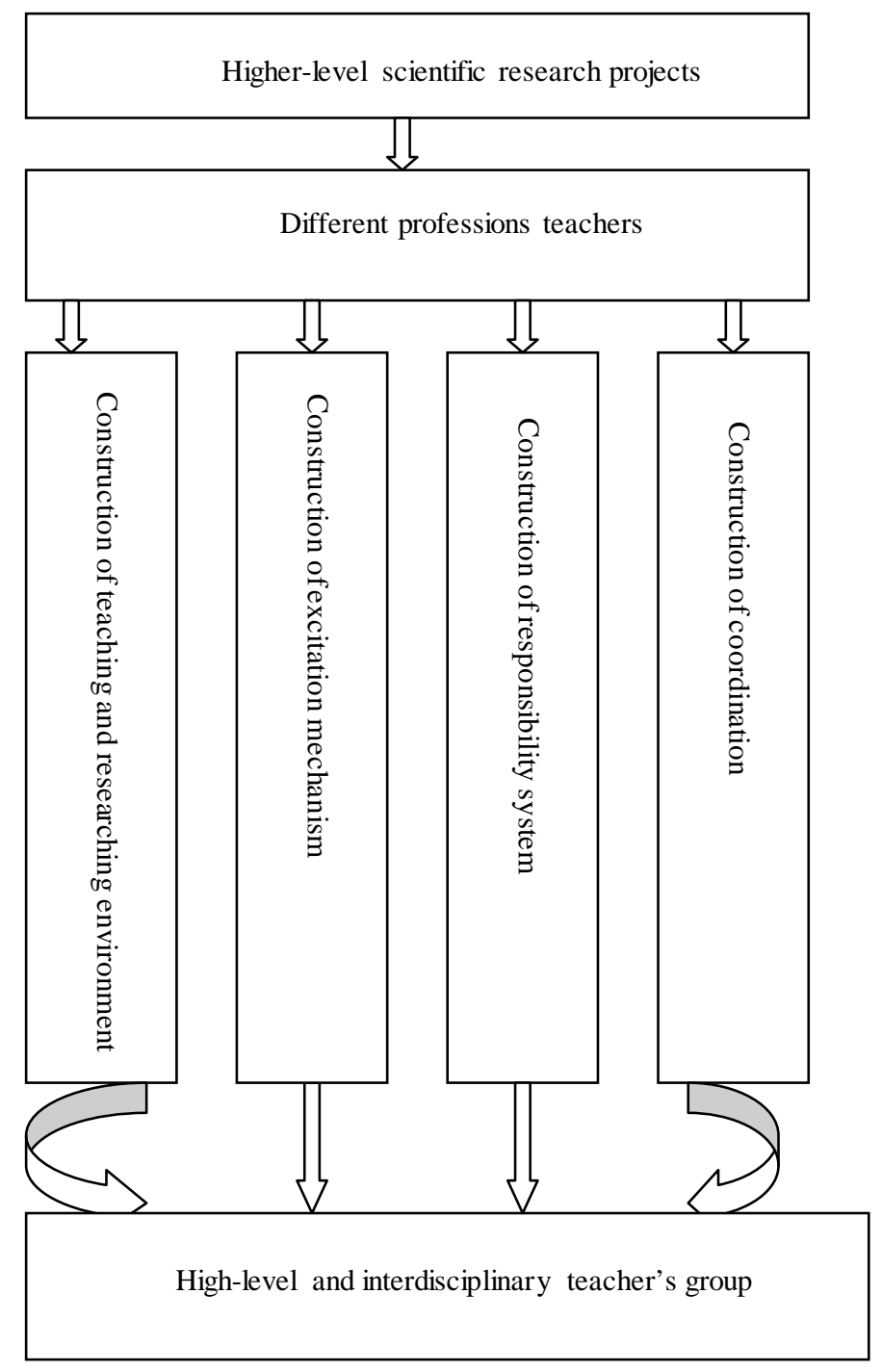

Fig. 1. The construction scheme of high-level and interdisciplinary teacher's group

\section{Construction of responsibility system}

High-level and interdisciplinary teacher's group is not always able to bring out high-level students. There are both teachers' responsibilities and students' own research problems. For high-level teachers, there are many kinds of roles, so that it takes a lot of time to deal with other things outside the school, and the time will be relatively less for the students. In order to deal with this situation, a clear responsibility mechanism must be established so that teachers can truly take 
responsibility for their students. Therefore, it is necessary to establish a responsibility system for interdisciplinary teachers to be responsible for the results and a clear assessment mechanism for teachers.

\section{Construction of coordination}

High level and interdisciplinary teacher's group depends on the spirit of group cooperation. In the interdisciplinary research team, teachers often start from their own specialties, study their own research problems, and then develop new methods and new means to solve the problem through the communication and cooperation with other professionals [7]. In the process of cultivating creative and interdisciplinary talent, teachers must have a sense of cooperation with other professional teachers, and more importantly, they must have the ability to cooperate with the academic circles.

\section{BUILDING A HIGH LEVEL AND INTERDISCIPLINARY STUDENT'S GROUP}

Taking the undergraduates of the college of engineering and technology as the research object in Tianjin Agricultural University, a high level and interdisciplinary student's group was built from the aspects of the selection model, training model, incentive mode, and management model (Fig.2).

\section{A. Construction of selection model}

It is very important to select excellent students to enhance the creative power [8]. In accordance with the principle of voluntariness, students of different majors in different colleges can participate in the selection. Students with innovative consciousness and practical ability are selected through various methods such as resume, written examination, production, and interview. Because different teachers have different research directions and subjects, they need different knowledge structure talents. According to the needs of interdisciplinary research projects, teachers can choose students from different majors to form teams.

\section{B. Construction of training model}

Students of different specialties should be encouraged to form a team to declare college students' innovative projects. At the same time, instructors publish a certain number of interdisciplinary projects, for students to choose their own projects, and build their own teams. The selected students independently declared the project plan, independently managed the research funds, and independently completed the scientific research task.

Meanwhile, according to the needs of interdisciplinary project research, the teachers carry out the relevant academic reports for the students and carry out the academic discussion. And the three level training models were established to cultivate high level and interdisciplinary student's group. Students come from different professional backgrounds, using their professional skills and perspectives to carry out information exchange, ideological collision and cooperation. In the process of completing the project, the coordination ability has been trained and the innovation ability has been improved[9].

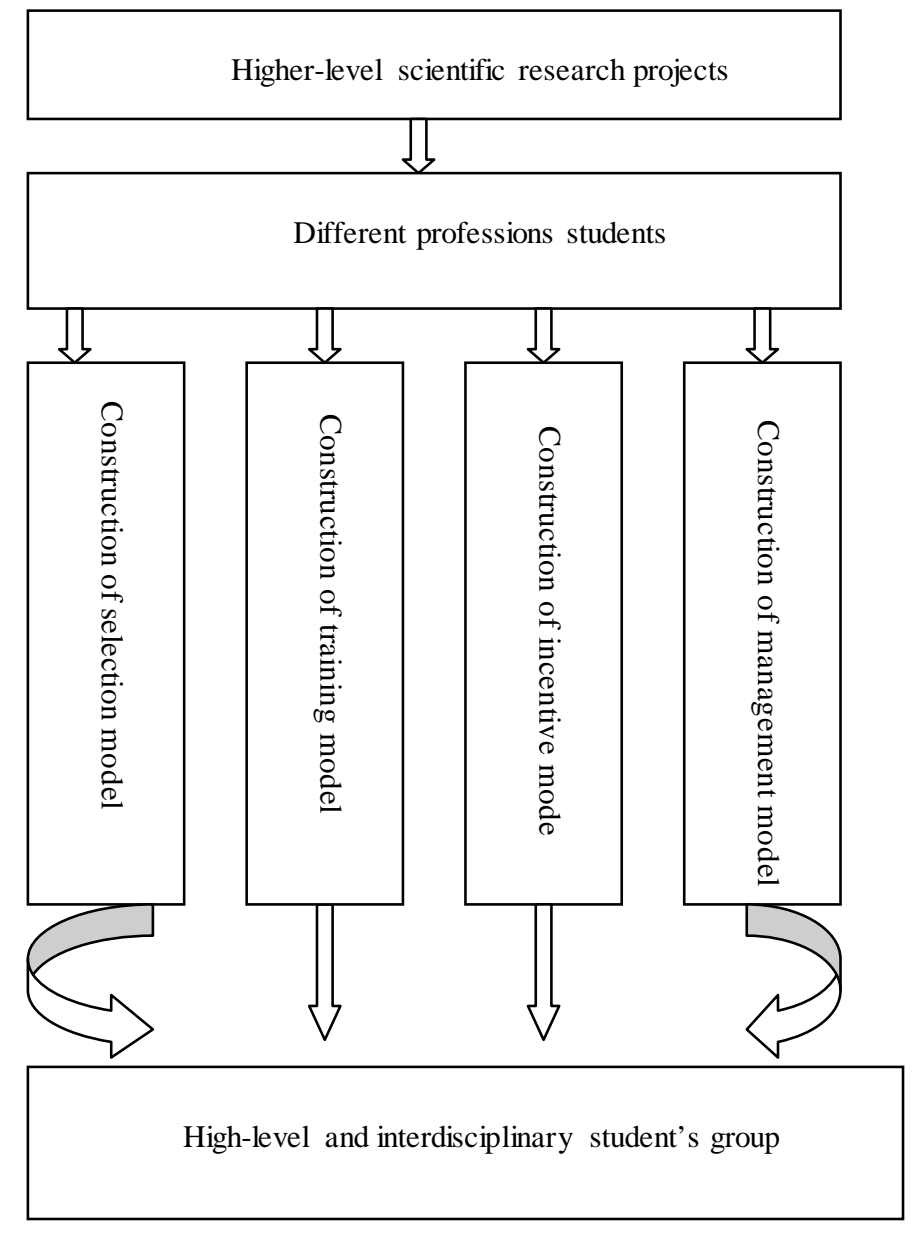

Fig. 2. The construction of high-level and interdisciplinary student's group

\section{Construction of incentive mode}

Students are the main body of interdisciplinary innovation projects. Students need to work longer hours in the group, and they also need to invest a lot of energy. There are few students who can really persist. It is very difficult to innovate the echelon construction of students. Therefore, it is necessary to establish a certain practice incentive mechanism in the early stage. On the one hand, the team tries to establish a hierarchical training platform for competition. On the other hand, it draws lessons from other colleges and universities in the practice of incentive measures. To establish a long-term and effective mechanism to encourage students to practice and innovate, it is recommended that students who have won prizes in practical competitions be rewarded with different grades.

\section{Construction of management model}

The sustainable development of the interdisciplinary innovation group of college students can not be separated from material and fund support, and it can not be separated from the standard management system to provide a good operating environment for the development of the group. Good group management is an important guarantee for cultivating creative and interdisciplinary talent of engineering students. Therefore, the management of interdisciplinary students' innovation 
group must be scientific and standardized. The college has to formulate rules and regulations for the operation of innovative group and the system of scientific research, project declaration, project establishment, process management, expense reimbursement and project completion.

Finally, the problems and difficulties encountered by teachers and students are systematically studied during the implementation of the subject. A questionnaire survey is carried out for students involved in interdisciplinary training, and statistical methods are used to analyze the results. According to the results, the training model is revised, supplemented and perfected.

\section{CONCLUSIONS}

In this paper, combined with the students of the College of basic science, the undergraduates of the college of engineering and technology were taken as research object in Tianjin Agricultural University. A combination of theory and practice, questionnaire and statistical analysis were adopted to study and establish a method and model to cultivate creative and interdisciplinary talents for engineering students based on Interdisciplinary science projects, so as to meet the needs of the training of innovative and interdisciplinary talents in twenty-first Century.

\section{ACKNOWLEDGEMENT}

This work was financially supported by the Major Teaching Reform Projects of Tianjin Agricultural University (2017-D-03), and the Education Reform and Innovation Development Funds of Tianjin Agricultural University (20170202).

\section{REFERENCES}

[1] Gong Lizhuan, Zhang Jing. Exploration of the cultivation of interdisciplinary talents. China University Teaching, 2008, 10:36-38. (In Chinese)

[2] Wu Di. Study on the practice of world-class universities in interdisciplinary professional course - Princeton University's "comprehensive science" curriculum plan [J]. Heilongjiang Researches on Higher Education, 2012, 10: 65-68. (In Chinese)

[3] Jiang Yongrong, Li Tianyu, Jiang Dongyun et al. Exploration and practice of establishing mode for scientific researching innovation group of undergraduate[J]. Journal of Guilin University of Electronic Technology, 2008, 28(4):376-378. (In Chinese)

[4] Hu Huojin. The construction of teachers' team and the cultivation of college students' innovative quality [J]. Fujian Forum, 2011, 12:197-198. (In Chinese)

[5] Zhang Xiaoping. Study on the teachers' factors of affecting the cultivation of college students' innovation ability [J]. China Adult Education, 2016, 7: 84-88. (In Chinese)

[6] Jiang Yongrong, Fang Cheng, Xia Jinhong. Exploration on cultivating innovative ability of undergraduate according to the idea of interdisciplinary [J]. Higher Education Forum, 2015, 7: 45-48. (In Chinese)

[7] He Nong. Study on the construction of teachers' creative team in Higher Vocational Colleges [J]. Heilongjiang Researches on Higher Education, 2008, 7: 118-120. (In Chinese)

[8] Zhao Yu. Exploration on establishment model of student team for the application and innovation of the new colleges [J]. Heilongjiang Agricultural Sciences, 2012, 6: 137-138. (In Chinese)

[9] Yang Renjie, Dong Guimei, Yang Yanrong, et al. The construction of innovation group and the sustainable development of innovation ability for engineering students[C]. International Conference on Economic Development and Education Management (ICEDEM 2017), 2017, 107: 352-355. 